\title{
PENGARUH MOTIVASI DAN PEMBERIAN KOMPENSASI TERHADAP KINERJA AGEN ASURANSI PADA PT. PRUDENTIAL LIFE ASSURANCE KECAMATAN RENGAT BARAT
}

\author{
Oleh: \\ Yenny Iskandar \\ Program Studi Manajemen, Sekolah Tinggi Ilmu Ekonomi Indragiri (STIE-I) Rengat \\ Email: yennyiskandar@stieindragiri.ac.id
}

\begin{abstract}
The study was conducted with quantitative methods, which describe the effect of motivation and compensation for the performance of agents at PT. Prudential Life Assurance Kabupaten Indragiri Hulu. By analyzing data using the instrument test, multiple regression, correlation coefficient, classic assumption test and hypothesis testing using SPSS version 24. From the results of the study with the regression equation $Y=$ $11.775+0.471 X 1+0.376 X 2 . a=11.775$ and if the independent variable is zero $(0)$ then the Agent's performance with 11.775 means that the Agent's performance is 11.775 if X1 (Motivation) and X2 (compensation) equals 0 (zero). b1 = Motivation regression coefficient of 0.471 indicates that each increase in Motivation by one unit and other variables remains, there will be an increase in Agent performance of $0.471 . b 2=$ regression coefficient of compensation of 0.376 indicates that for every increase of compensation of one unit and other variables, there will be an increase in Agent performance of 0.376. The correlation coefficient is known that $R$ is 0.451 which means that it has a moderate and direct relationship. and then tested with the Multiple Determination Coefficient (R2) is 0.468. this shows that (X1) Motivation and (X2) giving compensation together can contribute to the variable (Y) agent performance of $20.3 \%$. And the remaining $79.7 \%$ is influenced by other variables. Hypothesis testing at a significant level $=0.05 \%$ where $F$ arithmetic (7.904) $>F$ table (3.14) then Ho is rejected and Ha is accepted. This means that the motivation and compensation variables together have a significant influence on the performance of agents at PT. Prudential Life Assurance Kabupaten Indragiri Hulu
\end{abstract}

Keywords: Motivation, Giving Compensation and Performance

\begin{abstract}
Abstrak
Penelitian dilakukan dengan metode kuantitatif, yaitu menggambarkan tentang pengaruh Motivasi Dan pemberian kompensasi Terhadap kinerja Agen Pada PT. Prudential Life Assurance Kecamatan Rengat Barat Kabupaten Indragiri Hulu. Dengan menganalisis data menggunakan uji instrumen, regresi berganda, koefisien korelasi, uji Asumsi klasik dan uji hipotesis dengan menggunakan SPSS versi 24. Dari hasil penelitian dengan persamaan regresinya $Y=11,775+0,471 X_{1}+0,376 X_{2} . a=11,775$ dan jika variabel independen nol (0) maka kinerja Agen dengan 11,775 artinya kinerja Agen adalah 11,775 apabila $X_{1}$ (Motivasi) dan $X_{2}$ (pemberian kompensasi) sama dengan $0\left(\right.$ nol). $b_{1}=$ koefisien regresi Motivasi sebesar 0,471 menunjukkan bahwa setiap peningkatan Motivasi sebesar satu satuan dan variabel lain tetap, maka akan terjadi peningkatan kinerja Agen sebesar 0,471. $b_{2}=$ koefisien regresi pemberian kompensasi sebesar 0,376 menunjukkan bahwa setiap peningkatan pemberian kompensasi sebesar satu satuan dan variabel lain tetap, maka akan terjadi peningkatan kinerja Agen sebesar 0,376. Koefisien korelasi diketahui bahwa $R$ adalah 0,451 artinya memiliki hubungan yang sedang serta searah. dan selanjutnya diuji dengan Koefisien Determinasi Berganda $\left(R^{2}\right)$ adalah 0,468. hal ini menunjukkan bahwa $\left(X_{1}\right)$ Motivasi dan $\left(X_{2}\right)$ pemberian kompensasi secara bersama - sama dapat memberikan sumbangan terhadap variabel $(Y)$ kinerja Agen sebesar 20,3\%. Dan sisanya 79,7\% di pengaruhi oleh variabel lain. Uji hipotesis pada
\end{abstract}


taraf signifikan $\alpha=0,05 \%$ dimana $F$ hitung $(7,904)>F$ tabel $(3,14)$ maka Ho ditolak dan Ha diterima. Artinya variabel Motivasi dan pemberian kompensasi secara bersamasama memiliki pengaruh signifikan terhadap kinerja Agen pada PT. Prudential Life Assurance Kabupaten Indragiri Hulu.

\section{Kata Kunci : Motivasi, Pemberian Kompensasi dan Kinerja}

\section{PENDAHULUAN}

Karyawan sebagai inti dari Sumber Daya Manusia yang dimiliki organisasi, agar keragaman individu atau karyawan dapat dikelola dengan baik, maka manajer atau pimpinan perlu memahami bahwa dalam fungsi pengarahan, kunci agar fungsi tersebut dapat berjalan dengan baik adalah terletak pada motivasi dan kepuasan yang dimiliki setiap karyawan maupun kelompok dalam organisasi. Perusahaan dan sumber daya manusia merupakan dua hal yang saling membutuhkan. Jika sumber daya manusia berhasil membawa kemajuan bagi perusahaan, keuntungan akan diterima oleh kedua belah pihak. Bagi karyawan keberhasilan merupakan sarana untuk mengembangkan diri serta pemenuhan kebutuhan pribadinya. Sedangkan bagi perusahaan keberhasilan merupakan sarana untuk mengembangkan perusahaan serta bersaingnya perusahaan dengan perusahaan lain.

Di upayakan karyawan tersebut bekerja bukan karena untuk memenuhi kebutuhannya saja, ataupun sekedar mendapatkan bonus saja akan tetapi, karyawan harus memiliki kemauan untuk bekerja dan berusaha untuk mencapai target yang telah ditetapkan di perusahaan tersebut, serta menyalurkan kemampuannya untuk perusahaan. Karyawan yang bekerja hanya untuk memenuhi kebutuhannya saja tidak akan memberikan prestasi kerja yang maksimal bagi perusahaan. Berdasarkan permasalahan yang terjadi dalam perusahaan bahwa Kinerja agen asuransi masih rendah, hal ini dapat dilihat dari ketidak ketercapaian target dalam penjualan produk asuransi, sehingga dengan adanya fenomena tersebut diatas maka perusahaan perlu memperhatikan karyawan agen dengan memberikan motivasi dan kompensasi. Berikut ini jumlah premi asuransi pada PT. Prudential Life Assurance Kecamatan Rengat Barat Kabupaten Indragiri Hulu :

Tabel 1 : Jumlah Premi Asuransi Berdasarkan Target Agen/Tenaga Pemasar Pada PT. Prudential Life Assurance Kecamatan Rengat Barat Kabupaten Indragiri Hulu Tahun 2015-2018.

\begin{tabular}{|c|c|c|c|c|}
\hline No & Tahun & Premi Asuransi & $\begin{array}{c}\text { Jumlah } \\
\text { Perubahan }\end{array}$ & $\begin{array}{c}\text { Persentase } \\
\text { Perubahan }\end{array}$ \\
\hline 1 & 2015 & Rp. 382.765.000 & 145 & $76,82 \%$ \\
\hline 2 & 2016 & Rp. 411.215.000 & 82 & $33,5 \%$ \\
\hline 3 & 2017 & Rp. 329.500.000 & 182 & $54,94 \%$ \\
\hline 4 & 2018 & Rp. 114.800 .000 & 215 & $15,34 \%$ \\
\hline
\end{tabular}

Sumber : PT.Prudential Life Assurance Kecamatan Rengat Barat Tahun 2019

Berikut ini tabel jumlah Agen / Tenaga Pemasar pada PT. Prudential Life Assurance Kecamatan Rengat Barat Kabupaten Indragiri Hulu Tahun 2015-2018: 
Tabel 2 :Jumlah Agen/Tenaga Pemasar pada PT. Prudential Life Assurance Kec. Rengat Barat Kab.INHU Tahun 2015-2018.

\begin{tabular}{|c|c|c|c|}
\hline No. & Tahun & Jumlah Agen/Tenaga Pemasar & Persentase (\%) \\
\hline 1. & 2015 & 112 & 90,17 \\
\hline 2. & 2016 & 104 & 7.69 \\
\hline 3. & 2017 & 110 & 5.45 \\
\hline 4. & 2018 & 65 & 69,23 \\
\hline
\end{tabular}

Sumber: PT. Prudential Life Assurance Kecamatan Rengat Barat Tahun 2019

Dari tabel 1 di atas dapat dilihat jumlah Tenaga Pemasar (agen) pada tahun 2015 sampai dengan tahun 2018 mengalami fluktuasi. Berikut ini jumlah Pencapaian Target Agen/Tenaga Pemasar Untuk Mendapatkan Bonus serta jumlah agennya :

Tabel 3: Pencapaian Target Agen/Tenaga Pemasar pada PT. Prudential Life Assurance Kec.Rengat Barat Kab. INHU Tahun 2015-2018.

\begin{tabular}{|c|c|c|c|c|}
\hline No & Tahun & Pencapaian Target Agen & Bonus & Jumlah Agen \\
\hline 1 & 2015 & API 25.000.000 & Rp.1.500.000 & 33 Orang \\
\hline 2 & 2016 & API 35.000.000 & Rp.3.500.000 & 12 Orang \\
\hline 3 & 2017 & API 50.000.000 & Rp.5.000.000 & 8 Orang \\
\hline 4 & 2018 & API 34.000.000 & Rp. 735.000 & 7 Orang \\
\hline
\end{tabular}

Sumber : PT.Prudential Life Assurance Kecamatan Rengat Barat Tahun 2019

Dari tabel 3 di atas dapat dilihat pencapaian target agen dan jumlah agen yang mendapatkan bonus juga mengalami fluktuasi atau naik turun dan ini harus dilakukan motivasi yang lebih dari pihak perusahaan agar pencapaian target dan bonus untuk agen setiap tahunnya meningkat.

Berkaitan dengan pentingnya motivasi dan pemberian kompensasi maka hal ini perlu diperhatikan pada PT. Prudential Life Assurance Kecamatan Rengat Barat, yaitu sebuah perusahaan yang bergerak di bidang jasa asuransi jiwa, yang menawarkan dan menjual polis asuransi kepada masyarakat tidak lepas dari peran serta petugas lapangan asuransi atau agen asuransi yang mereka rekrut. Agenagen asuransi inilah ujung tombak perusahaan asuransi dalam menarik nasabah. Dengan adanya motivasi dan pemberian kompensasi yang tinggi, diharapkan peningkatan kinerjanya akan terus meningkat sehingga tujuan perusahaan dapat dicapai secara lebih efektif dan efesien. Dari uraian di atas peneliti akan melakukan penelitian dengan judul : "PENGARUH MOTIVASI DAN PEMBERIAN KOMPENSASI TERHADAP KINERJA AGEN ASURANSI PADA PT. PRUDENTIAL LIFE ASSURANCE KECAMATAN RENGAT BARAT".

\section{TINJAUAN PUSTAKA DAN HIPOTESIS}

\section{A. Kinerja}

Kinerja merupakan penampilan hasil karya seseorang dalam bentuk kualitas ataupun kuantitas dalam suatu organisasi. Kinerja dapat merupakan penampilan individu maupun kelompok kerja pegawai. Tiga hal penting dalam kinerja adalah tujuan, ukuran, dan penilaian. 
adalah :

Dimensi-dimensi yang dijadikan ukuran kinerja, menurut Nawawi (2007)

1. Tingkat kemampuan kerja (kompetensi) dalam melaksanakan pekerjaan baik yang diperoleh dari hasil pendidikan dan pelatihan maupun yang bersumber dari pengalaman kerja

2. Tingkat kemampuan eksekutif dalam memberikan motivasi kerja, agar pekerja sebagai individu bekerja dengan usaha maksimum, yang memungkinkan tercapainya hasil sesuai dengan keinginan dan kebutuhan masyarakat.

\section{B. Motivasi}

Motivasi kata dasarnya adalah motif (motive) yang berarti dorongan, sebab atau alasan seseorang melakukan sesuatu, dengan demikian motivasi berarti suatu kondisi yang mendorong atau menjadi sebab sesorang melakukan suatu perbuatan/kegiatan yang berlangsung secara sadar. (Nawawi, 2006:351)

\section{Pemberian Kompensasi}

Kompensasi adalah segala sesuatu yang diterima karyawan sebagai balas jasa kerja mereka. (Sedarmayanti 2010: 239)

\section{METODE PENELITIAN}

\section{Jenis dan Sumber Data}

Mengenai jenis data yang diperlukan dalam menyusun skripsi nantinya adalah :

1. Sumber Data Primer

Dalam penelitian ini adalah data yang diperoleh langsung dari riset lapangan perusahaan yang menjadi objek.

\section{Sumber Data Sekunder}

Data yang berkaitan dengan dasar teoritis yang diperoleh langsung dari perusahaan, struktur organisasi, meliputi sejarah singkat perusahaan, deskripsi pekerjaan serta bahan-bahan lain yang diperlukan dalam pembahasan masalah. Penelitian dokumen, penelitian mengadakan pengamatan pada dokumen yang berkaitan dengan objek penelitian. Literatur penelitian memperoleh data melalui literatur yang ada.

\section{Metode Pengumpulan Data}

1. Wawancara, yaitu dengan mengadakan wawancara langsung kepada pihak Instansi dalam hal ini Kepala Kantor dan karyawan agen nya.

2. Studi pustaka adalah mengumpulkan data dengan cara membaca dan mengutip teori - teori yang berasal dari buku dan tulisan - tulisan lain yang relevan dengan penelitian ini.

3. Questionery adalah dengan mengajukan suatu daftar pernyataan berupa angket kepada calon responden guna memperoleh data - data yang ada hubunganya dengan masalah yang dibahas. 


\section{Populasi dan Sampel}

Populasi yang penulis jadikan objek penelitian ini adalah seluruh agen sebanyak 65 orang yang ada pada PT. Prudential Life Assurance Kecamatan Rengat Barat Kabupaten Indragiri Hulu. Dikarenakan jumlah populasi yang sedikit maka penelitian mengambil sampel dengan metode sensus, yaitu semua populasi dijadikan sampel, yaitu sebanyak 65 orang agen.

\section{Analisis Data}

Dalam penelitian ini setelah data penulis kumpulkan, kemudian penulis kelompokkan atau spesifikasikan data - data tersebut, selanjutnya satu persatu dianalisa dengan menggunakan data kuantitatif untuk mengetahui apakah ada pengaruh Motivasi dan pemberian Kompensasi Terhadap Kinerja agen pada PT. Prudential Life Assurance Kecamatan Rengat Barat Kabupaten Indragiri Hulu. Dengan metode analisis regresi linear berganda yang dihitung dengan bantuan SPSS Versi 24 adalah sebuah softwares yang memudahkan kita di dalam riset mengenai Statistika.

\section{Uji Instrumen}

a. Uji Validitas

b. Uji Reliabilitas

2. Analisis Regresi Linear Berganda

3. Koefisien Korelasi Berganda (R)

4. Uji Asumsi Klasik

a. Uji Normalitas

b. Uji Autokorelasi

c. Uji Multikolinieritas

d. Uji Heteroskedastisitas

5. Pengujian Hipotesis / Signifikan pengaruh Simultan "Uji F"

\section{HASIL PENELITIAN DAN PEMBAHASAN}

\section{Analisis Regresi (Deskritif Statistik).}

Berdasarkan data SPSS Versi 22 di ketahui bahwa konstanta (a) adalah 11,775 dan koefisien $\mathrm{X}_{1}\left(\mathrm{~b}_{1}\right)$ adalah 0,471 dan koefisien $\mathrm{X}_{2}\left(\mathrm{~b}_{2}\right)$ adalah 0,376 dengan persamaan regresi berganda adalah $\mathrm{Y}=11,775+0,471 \mathrm{X}_{1}+0,376 \mathrm{X}_{2}$.

\begin{tabular}{|c|c|c|c|c|c|}
\hline \multicolumn{6}{|c|}{ Coefficients $^{\mathrm{a}}$} \\
\hline \multirow[b]{2}{*}{ Model } & \multicolumn{2}{|c|}{$\begin{array}{c}\text { Unstandardized } \\
\text { Coefficients }\end{array}$} & \multirow{2}{*}{$\begin{array}{c}\text { Standardized } \\
\text { Coefficients }\end{array}$} & \multirow[b]{2}{*}{$\mathrm{t}$} & \multirow[b]{2}{*}{ Sig. } \\
\hline & $\mathrm{B}$ & Std. Error & & & \\
\hline $1 \quad$ (Constant) & 11.775 & 2.347 & & 5.018 & .000 \\
\hline Motivasi & .471 & .126 & .440 & 3.745 & .000 \\
\hline Kompensasi & .376 & .121 & .268 & 2.279 & .026 \\
\hline
\end{tabular}

a. Dependent Variable: Kinerja Agen

$\mathrm{a}=$ konstanta sebesar 11,775 dan jika variabel independen dianggap nol (0) artinya Kinerja Agen adalah sebesar 11,775 apabila $\mathrm{X}_{1}$ (Motivasi ) dan $\mathrm{X}_{2}$ (Kompensasi) sama dengan 0 (nol). 
$\mathrm{b}_{1}=$ koefisien regresi Motivasi sebesar 0,471 menunjukkan bahwa setiap peningkatan Motivasi sebesar satu satuan dan variabel lain (Kompensasi) tetap, maka akan terjadi peningkatan Kinerja Agen sebesar 0,471.

$\mathrm{b}_{2}=$ koefisien regresi Kompensasi sebesar 0,376 menunjukkan bahwa setiap peningkatan Kompensasi sebesar satu satuan dan variabel lain (Motivasi ) tetap, maka akan terjadi peningkatan Kinerja Agen sebesar 0,376.

\section{Koefisien Korelasi (R) dan Koefisien Determinasi $\left(\mathbf{R}^{2}\right)$} Model Summary

\begin{tabular}{|l|c|r|r|r|}
\hline Model & R & R Square & Adjusted R Square & Std. Error of the Estimate \\
\hline 1 & $.451^{\mathrm{a}}$ & .203 & .177 & 2.369155 \\
\hline
\end{tabular}

a. Predictors: (Constant), Kompensasi, Motivasi

Pada tabel di atas diketahui bahwa $\left(\mathrm{X}_{1}\right)$ Motivasi dan $\left(\mathrm{X}_{2}\right)$ Kompensasi mempunyai hubungan dengan (Y) kinerja Agen. Dari nilai Koefisien Korelasi (R) adalah 0,451 artinya memiliki hubungan yang sedang. dan selanjutnya diuji dengan Koefisien Determinasi $\left(\mathrm{R}^{2}\right)$ adalah 0,203. hal ini menunjukkan bahwa $\left(\mathrm{X}_{1}\right)$ Motivasi dan $\left(\mathrm{X}_{2}\right)$ Kompensasi secara bersama - sama dapat memberikan sumbangan terhadap variabel (Y) Kinerja Agen sebesar 20.3\%. dan sisanya 79.7\% di pengaruhi oleh variabel lain yang tidak diteliti dalam penelitian ini.

\section{Uji Asumsi Klasik}

a. Normalitas

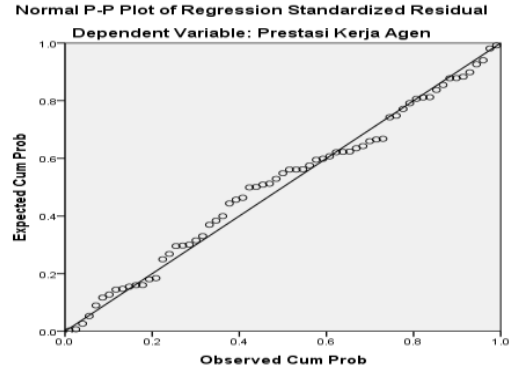

Dari data diatas dapat lihat P-P Plot pada output terlihat titik-titik menyebar di sekitar garis diagonal sehingga diputuskan model regresi berdistribusi normal. Untuk estimasi normalitas dapat diketahui menggunakan Kolmogorov-Smirnov Test.

b. Uji Autokorelasi

Model Summary ${ }^{b}$

\begin{tabular}{|l|c|r|r|r|r|}
\hline Model & R & R Square & Adjusted R Square & $\begin{array}{c}\text { Std. Error of the } \\
\text { Estimate }\end{array}$ & $\begin{array}{c}\text { Durbin- } \\
\text { Watson }\end{array}$ \\
\hline 1 & $.451^{\mathrm{a}}$ & .203 & .177 & 2.369155 & 2.157 \\
\hline
\end{tabular}

a. Predictors: (Constant), Kompensasi, Motivasi

b. Dependent Variable: Kinerja Agen

Dari tabel Durbin-Watson dan lihat kolom k (jumlah variabel independen) dan baris $\mathrm{n}$ jadi 2 dan 62. Nilai dU tabel sebesar 1,6621 sehingga batasnya antara dU dan 4-dU (1,6621 dan 2,157). Lihat output pada kotak Model Sumary terlihat nilai Durbin-Watson hitung sebesar 2,157 sehingga diputuskan bahwa terdapat autokorelasi dalam model regresi. 
c. Uji Multikolinieritas

\begin{tabular}{|c|c|c|}
\hline \multicolumn{3}{|c|}{ Coefficients ${ }^{a}$} \\
\hline \multirow[b]{2}{*}{ Model } & \multicolumn{2}{|c|}{ Collinearity Statistics } \\
\hline & Tolerance & $V I F$ \\
\hline (Constant) & & \\
\hline 1 Motivasi & 930 & 1.075 \\
\hline Kompensasi & 930 & 1.075 \\
\hline
\end{tabular}

a. Dependent Variable: Kinerja Agen

Model regresi bebas dari masalah multikolenieritas apabila nilai Tolerance lebih dari 0,10 dan nilai VIF kurang dari 10 yang berarti tidak ada korelasi antar variabel bebas. Lihat output pada kotak Coefficients. Semua nilai Tolerance di atas 0,10 dan nilai VIF kurang dari 10 sehingga disimpulkan bahwa model regresi bebas dari multikolenieritas.

d. Uji Heteroskedastisitas

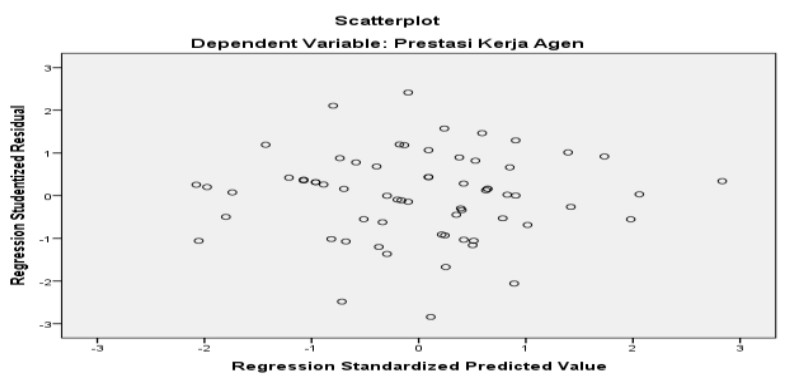

Lihat Scatterplot pada output terlihat titik-titik menyebar antara -2 hingga 1 dan tidak membentuk pola tertentu sehingga disimpulkan model regresi adalah atau tidak heteroskedastisitas.

\section{Analisis Hipotesis}

a. Uji hipotesis secara simultan (Uji Hipotesis dengan Uji " $F$ ")

ANOVA $^{\mathrm{a}}$

\begin{tabular}{|c|c|c|c|c|c|}
\hline Model & Sum of Squares & $\mathrm{df}$ & Mean Square & $\mathrm{F}$ & Sig. \\
\hline $1 \quad$ Regression & 88.730 & 2 & 44.365 & 7.904 & $.001^{\mathrm{b}}$ \\
\hline Residual & 347.999 & 62 & 5.613 & & \\
\hline Total & 436.730 & 64 & & & \\
\hline
\end{tabular}

a. Dependent Variable: Kinerja Agen

b. Predictors: (Constant), Kompensasi, Motivasi

Dari tabel diatas dapat dilihat F hitung yaitu 7.904 sedangkan $\mathrm{F}$ tabel yaitu 3,14 dapat diperoleh dengan menggunakan tabel $\mathrm{F}$ dengan derajat bebas (df) residual (sisa) yaitu 62 sebagai df penyebut dan df Regresion (perlakuan) yaitu 2 sebagai df pembilang dengan taraf signifikan 0,05 , sehingga diperoleh $\mathrm{F}$ tabel 3 ,14. karena F hitung $(7,904)>\mathrm{F}$ tabel $(3,15)$ maka Ho ditolak dan Ha diterima. Artinya variabel Motivasi dan Kompensasi secara bersama - sama memiliki pengaruh signifikan terhadap Kinerja Agen pada PT. Prudential Life Assurance Kecamatan Rengat Barat Kabupaten Indragiri Hulu. 


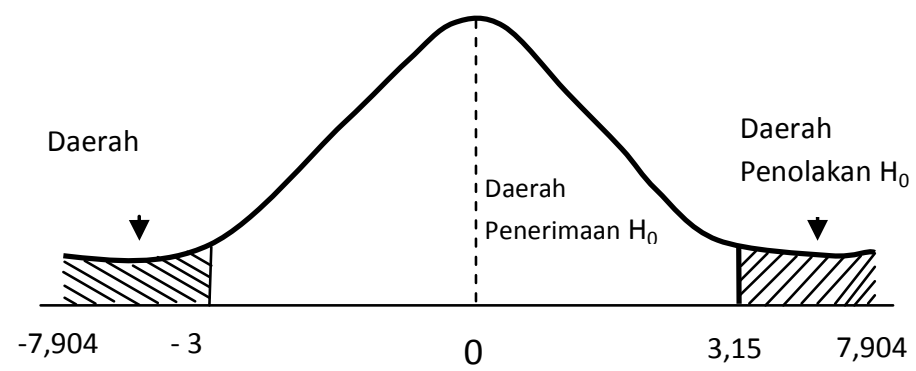

\section{PENUTUP}

\section{Kesimpulan}

1. Pada hasil penelitian diketahui bahwa responden memiliki persepsi tentang variabel kompensasi berada pada kriteria yang baik, hal ini terlihat dari nilai skor total jawaban responden sebesar 4,22. Ini artinya bahwa kompensasi yang diberikan perusahaan kepada karyawan sudah sesuai dengan kebutuhan. Hal ini terlihat dari setiap dimensi dimensi kompensasi seperti gaji, upah, insentif, tunjangan dan fasilitas. Namun demikian masih ada indikator yang belum optimal diantaranya adalah pemberian insentif diluar gaji dan pemberian gaji disesuaikan dengan beban kerja serta tanggungjawabnya.

2. variabel Motivasi di dapat nilai rata- rata sebesar 4,27 yakni termasuk kriteria setuju, artinya tingkat Motivasi termasuk sudah maksimal yang telah diberikan oleh perusahaan kepada agen/tenaga pemasar sehingga agen/ tenaga pemasar dapat meningkatkan kinerja dengan mencari nasabah di berbagai daerah yang berada di wilayah kabupaten Indragiri Hulu.

3. Variabel kinerja karyawan sebagian besar responden memiliki persepsi tentang kinerja karyawan berada pada kriteria yang baik, hal ini terlihat dari nilai skor total jawaban responden 4.27 Ini artinya bahwa kinerja karyawan sudah baik. Walaupun masih ada indikator yang belum optimal diantaranya adalah ketepatan waktu dalam menyelesaikan pekerjaan dan hasil kerja belum

\section{Saran} sesuai dengan target perusahaan.

1. Hendaknya Pihak PT. Prudential Life Assurance Kecamatan Rengat Barat Kabupaten Indragiri Hulu, lebih memperhatikan kondisi karyawan dengan memberikan Motivasi agar dapat memperlancar pekerjaan.

2. Hendaknya PT. Prudential Life Assurance Kecamatan Rengat Barat Kabupaten Indragiri Hulu lebih meningkatkan pemberian Kompensasi di dalam bekerja agar Kinerja Agen berjalan dengan baik dan memuaskan. Pelaksanaan pemberian kompensasi kepada karyawan oleh perusahaan sudah berjalan dengan baik. Namun demikian masih ada indikator untuk komponen gaji yang harus diperbaiki oleh perusahaan diantaranya adalah pemberian insentif di luar gaji serta pemberian gaji disesuaikan dengan beban kerja dan tanggungjawab karyawan dalam melaksanakan pekerjaan.

3. Perlu adanya upaya peningkatan Kinerja Agen dengan adanya motivasi dan insentif yang lebih dari pimpinan kepada karyawan sehingga hasil kerja yang dicapai dapat memenuhi kualitas dan kuantitas sesuai dengan standar yang ditetapkan Perusahaan. Pelaksanaan kinerja karyawan di perusahaan sudah berjalan dengan baik untuk komponen melakukan pekerjaan dengan profesional walaupun masih ada indikator yang harus diperbaiki yaitu masalah ketepatan waktu dan hasil kerja dalam menyelesaikan pekerjaan. 


\section{REFERENCE}

Handoko, T Hani, 2012, Manajemen Personalia dan Sumber Daya Manusia, BPEE, Yogyakarta.

Hasibuan, Malayu, 2009, Manajemen Sumber Daya Manusia, Bumi Aksara, Jakarta.

Mangkunegara, Prabu Anwar, 2005, Manajemen Sumber Daya Manusia Perusahaan, Remaja Rosda karya, Bandung.

Nawawi, Hadari, 2006, Evaluasi Dan Manajemen Kinerja Di Lingkungan Perusahaan Dan Industri, Gadjah Mada University Press. Yogyakarta.

Prakoso Medi, 2016, Pengaruh Motivasi Kerja Dan Kompensasi terhadap Kinerja Karyawan Percetakan Art Studio Jakarta Pusat.

Robbins, S dan Coulter, M, 2007, Manajemen, EdisiKedelapan, Penerbit PT, Indeks, Jakarta.

Sedarmayanti, 2010, Prinsip-prinsip Perilaku Organisasi, Mandar Maju Bandung.

Siagian, Sondang P, 2009, Manajemen Sumber Daya Manusia, Penerbit Bumi Aksara, Jakarta.

Simamora, Henry, 2008, Manajemen Sumber Daya Manusia, Penerbit YKPN Yogyakarta.

Sutiono, Agus, 2011, Memahami Good Governance Dalam Perspektif Sumber Daya Manusi,. Yogyakarta, Gava Media.

Wibowo, 2014, Manajemen Kinerja Edisi Kelima, PT Rajagrafindo persada, Jakarta. 